\title{
Juan José Rastrollo Suárez, Crisis, reacción y evolución: el teletrabajo en el sector público
}

\author{
Miguel Ángel Andrés Llamas \\ Universidad de Salamanca (España) \\ ORCID: https://orcid.org/0000-0001-8824-2917 \\ mllamas@usal.es
}

\section{NOTA BIOGRÁFICA}

Investigador posdoctoral Margarita Salas en el Área de Derecho Administrativo de la Universidad de Salamanca.

\section{RESUMEN}

Recensión del libro de Juan José Rastrollo Suárez, Crisis, reacción y evolución: el teletrabajo en el sector público, Thomson Reuters Aranzadi, 2021, 183 pp.

\section{PALABRAS CLAVE}

Teletrabajo; sector público; administración electrónica; gestión por objetivos.

\begin{abstract}
Review of the book from Juan José Rastrollo Suárez, Crisis, reacción y evolución: el teletrabajo en el sector público, Thomson Reuters Aranzadi, 2021, 183 pp.
\end{abstract}

\section{KEYWORDS}

Teleworking; public sector; e-government; management by objectives.

La pandemia de la COVID-19, por razones obvias, ha revitalizado el interés por el teletrabajo tanto en el sector privado como en el sector público. Fruto de esta realidad sobrevenida se aprobó el Real Decreto-ley 28/2020, de 22 de septiembre, de trabajo a distancia, que fue tramitado como proyecto de ley y dio lugar a la vigente Ley 10/2021, de 9 de julio, de trabajo a distancia, en cuya disposición adicional segunda se excluye de su aplicación al personal laboral al servicio de las Administraciones Públicas.

Poco después llegó el turno al sector público con la aprobación del Real Decreto-ley 29/2020, de 29 de septiembre, de medidas urgentes en materia de teletrabajo en las Administraciones Públicas y de recursos humanos en el Sistema Nacional de Salud para hacer frente a la crisis sanitaria ocasionada por la COVID-19. Más recientemente, ha sido sometido a trámite de información pública un proyecto de Real Decreto por el que se regula el teletrabajo en la Administración del Estado.

A tenor de estos precedentes, la monografía del profesor Rastrollo Suárez se publica en un momento de singular trascendencia para nuestras Administraciones públicas. Pero, lejos de lo que pudiera parecer, no estamos ante un trabajo pergeñado para dar respuesta a meras necesidades coyunturales, sino que aborda el fenómeno del teletrabajo atendiendo a su proyección estructural en la gestión del empleo público.

La principal perspectiva de análisis es la jurídico-administrativa, si bien a lo largo de los cinco capítulos que componen la obra se entreveran algunos elementos procedentes de otras disciplinas lindantes, no solo 
jurídicas, que enriquecen el resultado, en el buen entendido de que la doctrina administrativista ya no puede operar al margen de la más amplia visión de las políticas públicas.

En efecto, una de las aportaciones más valiosas de esta monografía es que, partiendo de la centralidad del tratamiento jurídico-administrativo, proporciona al lector un conocimiento contextual, integral y holístico del fenómeno del teletrabajo y de sus implicaciones en la organización administrativa, en el marco de los cambios tecnológicos cristalizados en el paradigma de la Administración electrónica. A ello contribuye también la doble mirada diacrónica y comparada contenida en la obra. Cabe destacar la precisa exposición de Ios avatares normativos de Estados Unidos, Alemania, Francia, Italia (referencia en la materia), Portugal y Reino Unido, países en los que se ha implementado el teletrabajo en la Administración con distinta intensidad y variable grado de especificidad normativa respecto del sector privado.

Igualmente ilustrativa es la exposición sistemática de la normativa autonómica en la materia. A la luz de este exhaustivo estudio, cabe concluir que el bagaje organizativo de las Comunidades Autónomas, algunas de ellas pioneras en el diseño y regulación del teletrabajo, representa una oportunidad de aprendizaje institucional para hacer frente a los retos futuros.

El autor apunta diversos factores que justifican la apuesta por esta modalidad de trabajo en la Administración, como la conciliación de la vida personal, familiar y laboral o la reducción de desplazamientos y, en consecuencia, de la huella ecológica; pero también deja constancia de los posibles efectos negativos del teletrabajo, como la existencia de riesgos psicosociales asociados al aislamiento.

Con todo, la principal preocupación de la obra consiste en escudriñar las implicaciones jurídicas del teletrabajo en el empleo público. Como en tantas otras ocasiones, una vez más la singular naturaleza de la Administración requiere una posición de cautela al dirimir cómo extrapolamos fenómenos, conceptos o categorías generales que trascienden al funcionamiento administrativo, es decir, la posición metodológica propia del Derecho administrativo. Suele afirmarse que el Derecho administrativo es un Derecho de equilibrio -quizá todo Derecho lo es-, delicada naturaleza que explora el autor al diseccionar las presiones encontradas que el teletrabajo ejerce en la Administración.

Una de las preguntas decisivas en los procesos de implementación del teletrabajo es la identificación de los puestos susceptibles de esta modalidad laboral. En el ámbito de la Administración pública, la respuesta se halla indefectiblemente condicionada por el interés general que aquella encarna. Este interés se plasma, entre otros extremos, en la necesidad de garantizar una atención adecuada a la ciudadanía en muy diversas áreas de la actividad administrativa, sin que pueda obviarse la persistencia de la denominada brecha digital y el fenómeno de la despoblación. Como apunta el autor, el caso aragonés es uno de los pocos que incorpora la necesidad de contemplar la viabilidad del teletrabajo en las relaciones de puestos de trabajo, instrumento que debería adquirir una mayor flexibilidad para cumplir este cometido.

Especial interés reviste el análisis que realiza el autor sobre el resurgimiento de las «necesidades de servicio» y su exploración como concepto jurídico indeterminado que adquiere renovado vigor jurídico-práctico para dirimir las solicitudes de teletrabajo. La exposición sistematizada de la jurisprudencia, quizá no muy extensa pero sí de enorme trascendencia prospectiva, adereza el estudio en este punto y en toda la materia abordada.

Como también se advierte en la monografía, no menos importante en el diseño y ejecución de los programas de teletrabajo resultará el ejercicio de la potestad discrecional de autoorganización, derivada del principio constitucional de eficacia, así como la función de control, que se plasma sobre todo en la elaboración de sendos informes, por ejemplo, sobre la autorización de esta modalidad.

El teletrabajo plantea en la Administración pública un desafío pendiente en el campo de la dirección y gestión públicas, que tiene que ver con la orientación del trabajo realizado a distancia por las y los empleados públicos al cumplimiento de objetivos previamente establecidos. El hecho de que el profesor Rastrollo Suárez sea un reconocido especialista en los sistemas de evaluación del desempeño facilita la tarea de abordar este desafío desde la perspectiva jurídico-administrativa. En este sentido, el autor señala la importancia del plan o programa de teletrabajo como el instrumento idóneo para materializar dicha evaluación.

El paradigma de la gestión por objetivos que comporta el teletrabajo puede generar una cierta tensión, un precario equilibrio, con el específico estatuto del empleado público teletrabajador, cuyos derechos y deberes precisan de concretos desarrollos normativos, de manera destacada en todo lo relativo a la formación, a la dotación de los medios tecnológicos necesarios y a las garantías de los derechos digitales y, en particular, del nuevo derecho a la desconexión digital. También el autor se ocupa con solvencia de estos extremos, así como del profuso tejido orgánico que ya se ha venido gestando en el ámbito autonómico para canalizar la implementación de esta modalidad de prestación laboral. 
El libro no incurre, a mi modo de ver, en un error demasiado frecuente en la literatura académica, no solo en la jurídica, que es la de concebir el objeto de estudio con un fetiche. Si bien es cierto que el autor se muestra partidario de impulsar el teletrabajo y tilda a España de país rezagado en cuanto a su regulación, en todo momento contempla las dificultades y los problemas reales y potenciales que suscita la implementación del teletrabajo en la Administración.

Sin ser una obra en exceso prescriptiva, se constata en todo momento la preocupación del autor por la praxis jurídico-administrativa. Una vez más se demuestra que la profunda reflexión dogmática no está reñida con la aplicabilidad práctica de la investigación; al contrario, aquella opera siempre como una garantía de realismo. No debería ser otra manera si convenimos que el Derecho es siempre una técnica de organización social; y el Derecho administrativo, una técnica -quizá la más determinante- al servicio de la organización administrativa y de sus relaciones con las personas. Se advierte del mismo modo que la investigación académica de calidad resulta indiferenciable de lo que se ha dado en llamar transferencia del conocimiento.

En alguna ocasión se refiere el autor a la necesaria colaboración de los niveles político y administrativo para asegurar un diseño óptimo y el buen desempeño de los programas de teletrabajo, a lo que habría que añadir la incidencia de otros factores extrajurídicos, como la suficiencia presupuestaria para acometer el reto tecnológico.

Sin perjuicio de tener muy presentes estos y otros obstáculos jurídico-organizativos de su implementación, parece desprenderse del conjunto de la obra la conveniencia de concebir el teletrabajo con mayor ambición que una mera situación administrativa en el empleo público, esto es, la necesidad virtuosa de imaginar una nueva oportunidad para la reforma y modernización de la Administración, tan anhelada en las últimas décadas como difícil de materializar, un proceso de transformación que habrá de materializar el paradigma de la gestión por objetivos y resultados.

En definitiva, se trata de una obra sólida que arrojará luz a los operadores jurídicos en la materia, al mismo tiempo que debería convertirse en una herramienta de consulta indispensable para los responsables políticos, el personal directivo de todas las Administraciones y las organizaciones sindicales a la hora de diseñar instrumentos normativos y acuerdos colectivos que impulsen el teletrabajo en el sector público, en todos los niveles competenciales, con eficacia y las debidas garantías.. 